\title{
Architecture for Informal Tourism - Mild Occupation of Landscape through Campsites
}

\author{
By Xavier Martín Tost
}

\begin{abstract}
The IAM Research group (Investigation in Mediterranean Architecture), from the La Salle-Ramon Llull University in Barcelona, is developing its research on the architecture of touristic settlements. Its aim is to regenerate the coast of Catalonia by examining the close relationship between heritage and landscape. Part of this research has been developed through case studies of campsite settlements as a typology of the mild occupation of natural environment. Main particularity of this kind of settlements is that their implantation in landscape is based on a duality between formal designs provided by architects and informal occupation developed by users in their private plots.

In order to recognize qualities of these lightweight and dual architectures of the 1960s, this paper is focused on a comparison between two examples which landscapes are completely opposite. The aim of this research is to raise awareness of the values of these kind of settlements: temporality, nature and informal occupancy.
\end{abstract}

Keywords: Campsite, Informal tourism, Landscape preservation, Mediterranean architecture, Temporary cities.

\section{Introduction}

The aim of the IAM Group (Investigation on Mediterranean Architecture, La Salle - Ramon Llull University) is to analyse and publish information about the architecture of Mediterranean coast, related to both site planning and building construction. Since 2008, the IAM Group has been collaborating with different organizations and institutions, both public and private, related to general topics of the same context. The group is currently developing an R\&D project called "Strategies for the Sustainable Regeneration of Tourism Settlements in the Mediterranean coast" (IAM 2012-14).

Its main goal is to propose well-grounded strategies for the architectural transformation of the whole coast. These strategies are set by comparing different case studies (usually disused buildings) entailing disadvantages common in many different coastline municipalities. Actually, it is possible to activate the urban regeneration of the coastal environment on the basis of proposals regarding the conversion of these buildings into public landmarks with new uses. All of these proposals are developed following sustainable criteria taken from traditional Mediterranean architecture. So that, this research is based on a "zoom in/zoom out" process that not only permits the

\footnotetext{
* Architect, Research Group IAM, University Ramon Llull, Spain.
} 
development of specific constructive projects, but also solves landscape and urban problems on a larger territorial scale.

A deep analysis of the Catalan coast, reflected on a typological map of the land (500km length of coast and $20 \mathrm{~km}$ width of land) is the first step of the methodology adopted in the present study (Figure 1). Common problems are indicated in the map, enabling the detection of those case studies showing enough potential to become points of urban regeneration. All of these buildings or settlements are also classified into four different groups according to their characteristics: residential, public facilities, infrastructures and landscape.

Figure 1. Typological Map of Catalan Coast

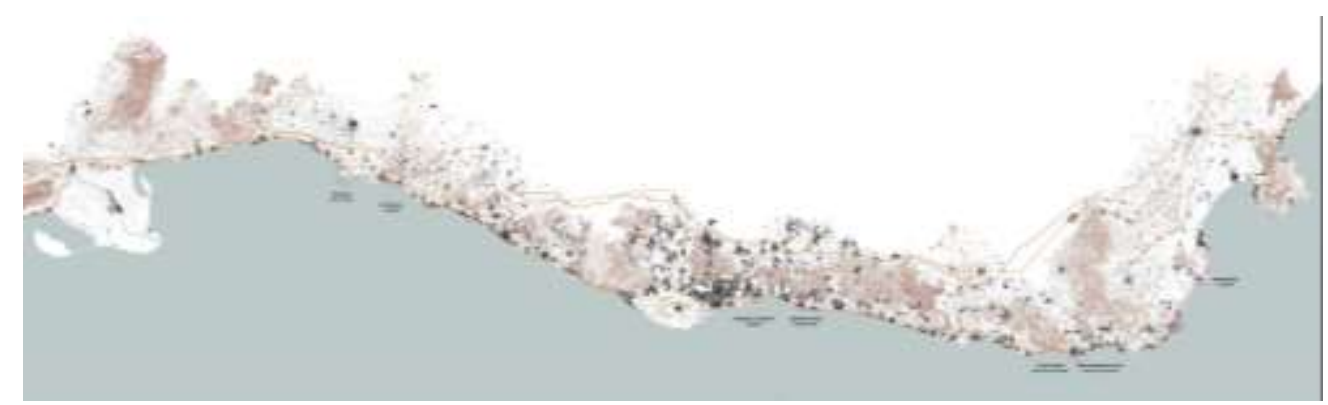

Source: Group IAM, R\&D project (IAM Group 2015).

Focusing on the Landscape typology, the related analysis group incorporates those zones or urban elements closely related to nature and their public uses. Main examples analyzed in this group are seafronts, coastal walking roads, gardens, golf courses and campsites. In this article, the analysis and research results in relation to two specific campsite case studies and common strategies for landscape preservation detected in these designs are presented.

\section{Campsites: Landscape, Tourism and Architecture}

"The ease to assemble and disassemble is the thing about travelling... Nomadism has the power to move my house to and from. [...] The work of doing it yourself socializes the idea of group and community".

Interview to Architect Carles Ferrater (Ollé and Mataix 2011)

The origin of campsites as a settlement started approximately in the 1920s. Camping's antecessor is undoubtedly hiking, based on long mountain walks that lasted several days. Its main objective was to enjoy nature with the possibility of inhabiting an outdoor space. This form of occupying the environment was inappreciable in the majority of the cases as overnight stays mainly took place in these locations where the topography and vegetation provided the most comfortable conditions for. Accommodation was only 
lightweight tents that had to be carried on foot. The following day, after the end of the stay, the original features of the natural environment remained unaltered.

Some years later, the increase in popularity of hiking as a sport led to the establishment of some boundaries that enabled big organized groups to hike and camp. However, these stays easily lost their sense of sport camps towards more touristic ones providing leisure in nature (Codina 1964). These new settlements would transform the way of staying out in the open, towards different, more stable and durable dynamics. However, an effort was also made to keep the original criteria of temporality and preservation of natural environment (Figure 2).

This new form of occupation became similar to other settlements that already existed in the coastline areas; those providing service zones and beach baths (Figure 3). These sectors were based on a balance between two different kinds of buildings, with opposite scales and characters. On one hand there were pavilions, which corresponded to those fixed elements and related to general patterns. These solved the needs of restoration, common leisure and public uses. On the other hand, there were huts, which formed an extensive network of little refuges related to a specific form of private use. These solved particular needs such as changing rooms, storage or shaded areas.

Figure 2. (left) Hiking in the Pyrenees, 1964

Figure 3. (right) Beach Baths in Salou, 1929

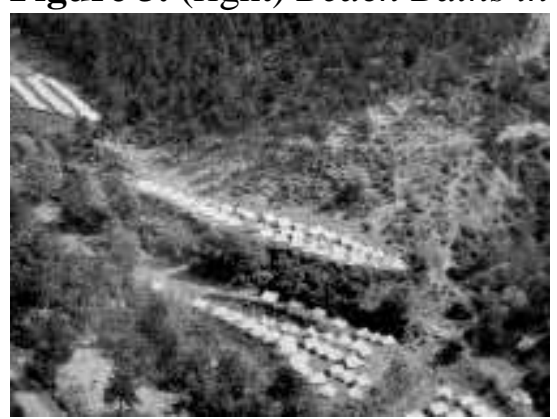

Source: Codina 1964.

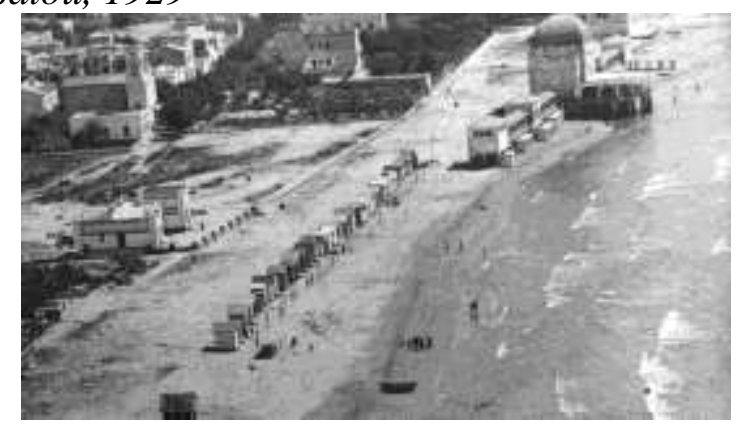

Source: J. Gaspar Serra (1929). ICC, RF.16719

Regardless of whether the project was mainly focused on large pavilions or small huts, and which had the most important role in it, this dual system was quickly adopted by campsites due to its simplicity and its low negative impact on the environment. A series of fixed elements are spread over the sector, providing common services, along with a net of other private lightweight lodgings, such as tents or caravans.

In the case of the Spanish Mediterranean coast, the origin of campsites dates back to the late 1950s. By that time, this kind of tourism had forged the concept of an ideal holiday for many Spanish families as the camping settlements enabled users to enjoy the landscape in a really communal feeling. Furthermore, campsites offered some triggers for the social and economic revival of a depressed and closed country.

At that time, Spain was still under dictatorship, but there was a growing awareness of the pleasant climate and lore of which Spain had to offer and this 
promoted foreign tourism as a driving force for change. So, Spain began to open its doors to foreigners in terms of cultural, social and economic values. These sociopolitical conditions have been proven crucial for the establishment of coastal campsites as massive leisure destinations, evolving from the previous facilities for spending the night in nature, such as hiking camps and beach baths (Figure 4).

Figure 4. (left) Campsite El Delfin Verde, 1963

Figure 5. (right) Campsite Cala Gogó - El Prat, 1975

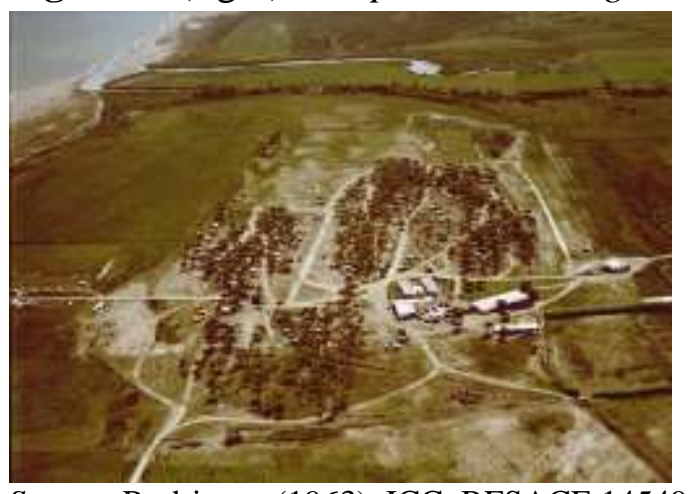

Source: Rodriguez (1963). ICC, RFSACE.14549.
Source: Campsite private archive.

In a few years, the number of campsites increased rapidly. As a result, architects were needed to define an organized design for these temporary settlements. All their projects had to be perfectly designed to facilitate the admission of huge numbers of tourists. Furthermore, as temporal occupations, these designs require a clear composition that could facilitate user orientation, and also optimal functionality and distribution of uses in larger areas (Figure 5). For this reason, architects had to base their designs on elements taken from traditional Mediterranean architecture and urbanism.

On the other hand, all users also had to mildly transform their own plot in order to reach the comfort standards necessary to inhabit it. With very simple materials and systems, users developed imaginative proposals in a close link between necessity and will. So, campsites became a great example of local settlements and construction, both due to their architectural efficiency and the concept of private occupation of the camper.

Thus, it is really interesting to recognize qualities of this lightweight Mediterranean architecture of the 1960s and also elevate the patrimonial value of its application to the development of campsites and preservation of landscape. Finally, some of these settlements disappeared, other returned to their natural background or remained open but in a process of transformation that changed their original features: temporality, nature and informal occupation. 


\section{Case Studies: El Toro Bravo and Cala Gogó}

\section{Landscape}

"The campsite is perhaps the form of tourism that least impairs the physical environment or at least does not irreversibly deteriorate it, although the potential to alter the landscape should not be underestimated".

(Miranda 1985: 172-173)

The most important element that defines campsites is the natural environment in which they are placed. Unlike other touristic settlements, campsites are characterized by the element of merging with the natural landscape. The latter is accomplished by an organized dispersion of small elements, not aiming to modify the characteristics of the landscape, but respecting them and following the natural order. Protection and respect for nature is such a fundamental value for campsites that treating the environment with thoughtfulness is understood as a basic condition of their existence. Furthermore, this objective is translated into comprehending and following the landscape's specific requirements. In campsites, environmental cautiousness is both a condition and a determinant at the same time.

This analysis focuses on two representative examples of this duality, being located to landscapes standing opposite to each other (Figure 6). On one hand, the "El Toro Bravo" campsite (Architect F. Mitjans 1962, Barcelona) was located on a flat land close to the sea and under a pine forest. On the other hand, the "Cala Gogó" campsite (Architects A. Bonet and J. Puig 1961, Girona) is still located on a sloped hill towards the sea.

Figure 6. Comparison Between Landscapes, Case Studies El Toro Bravo

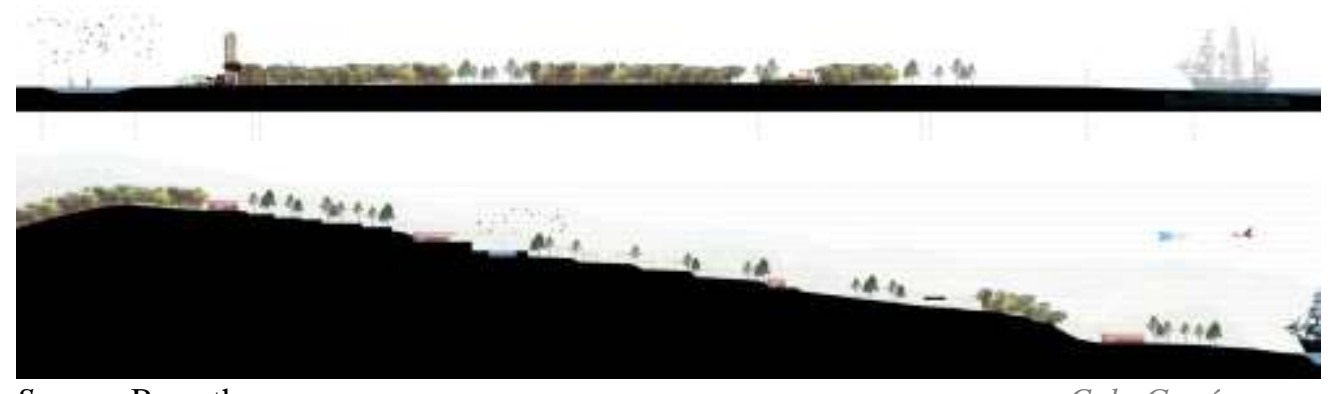

Source: By author.

Cala Gogó

In the Mediterranean climate of these campsites, the comfort necessities are mainly related to sun protection (generation and provision of shade) and the provision of an almost flat plot in order to develop all camping related activities. These two features are necessary in this kind of settlement, so if natural environment did not provide these requirements, the architects had to adapt it as respectfully as possible without interfering with its natural values. 
On the one hand, the location of El Toro Bravo was defined by a fragile context of beaches, dunes, pine forests and water (Figure 7). All of these were dynamic and easily modifiable elements. Thus, under those pine forests, the perks of shaded areas and flat plots were directly available. On the other hand, the location of Cala Gogó was defined by a tectonic landscape. Its high topography and lack of vegetation, due to previous agricultural usage, did not easily enable the construction of a new settlement of this kind (Figure 8). In this case, the architects modified its topography following local systems of adaption, and also added some formal elements to provide enough shade.

Figure 7. (left) Pine Forest in Llobregat, 1992

Figure 8. (right) Sloped Lands in Calonge, 1961
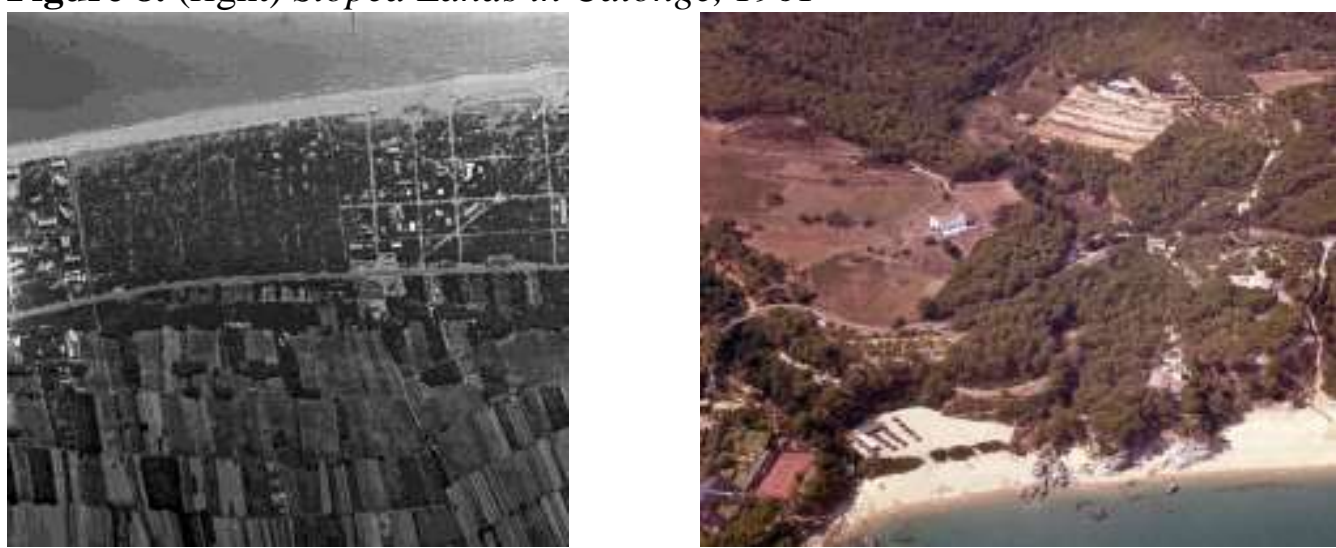

Source: COAC 1992.

Source: Rodriguez (1961). ICC, RFSACE.19059

It is also important to note that these landscapes were part of an environment of high apparent natural activity. For many years, their formation and evolution were defined by the actions of their previous occupiers. As Jaime Dern (1992) appointed in an article published on Quaderns d'Arquitectura $i$ Urbanisme:

"We must remember that nature has never been a virgin. Landscapes such as Tuscany, so admired today, are hidden under the appearance of a "natural" long task of human handling (cypress plantations, road layouts, profile alterations...). Transformation processes that today contribute to create an ambiguous dichotomy between what is natural and what is artificial".

Pine forests were planted to fix dunes, lagoons were dried and modified in order to adapt river shapes, topography platforms were originally adapted for agricultural motives, or even roads, path ways and irrigation channels were conditioned by agricultural divisions (Valverde 1997). All of these elements were artificially modified, but as time went by they became part of the natural landscape itself.

Therefore, very few of those elements defining natural environments could be considered natural in their essence. Landscape has always been modified by 
humans according to their needs; the grade of intervention is what nowadays can be defined as natural or artificial considerations. The responsibility of the architects was to recognize those values in order to take advantage of the close relationship between users and the landscape in order to accommodate a temporary settlement in those supposedly virgin natural territories.

\section{Temporary City}

"Urban planning and architecture have been developing their works until this century relying on the principle that nature, admired, could also be completed, until reaching a balanced territory. [...] So that, following question does not seem useless: is it a matter of masterplan or plots?"

Architect Rosa Barba (Barba 1992)

Campsites formed a living system -a lightweight city- based on a duality between formal and informal architecture. Architects defined those parameters that would enable the temporal occupation of landscape, following internal organization, user orientation, zooning and landmarks. However, it was the users who finally adapted their own private plots using non regulated tools to solve their particular needs of comfort. Users stayed in the campsites forming communities in a natural environment, consisting of two different layers that were developed together: city system and plot system.

The city system was based on those links and uses developed in the context of a more general point of view, in relation to the landscape's boundaries and external context. Architects defined some features that made the campsites more orderly, like temporal cities. By concentrating main activities in common buildings, the latter could be transformed into central points of intensive public usage. Consequently, users could delicately modify their individual plots in order to adapt their own basic functions of relax and leisure, as part of their private plot system. Thus, users could approach a particular way of living: inhabiting nature.

In the case of El Toro Bravo, the existing pine forest provided shade and also defined fixed distances for the tents between the trees, forming a sinuous settlement. Its limits were defined by nature, located between lagoons and the beach, also being part of the settlement's amenities. In order to reach an effective architectural design in the given flat territory, a walkway from the main entrance was designed, crossing the campsite diagonally and connecting all common buildings. This walkway supported all public uses and became a landmark for user's orientation (Figure 9). 
Figure 9. General View and Composition, El Toro Bravo, Viladecans

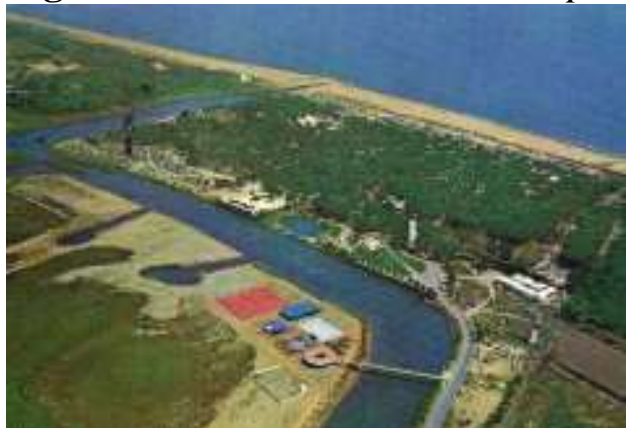

Source: Campsite private archive

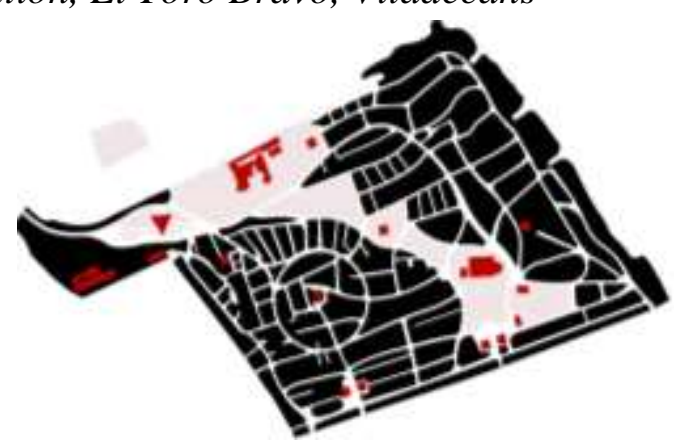

Source: By author.

In the case of Cala Gogó, the high topography established horizontal platforms which followed level curves. Thus, the shape of the settlement was defined by a pattern which was perpendicular to its slope and provided sights over the sea. Its limits were defined by the two existing streams that descended onto the beach. In the center of the settlement a singular building was placed that hosted the provision of all common services in a unique way. This central area gradually became a public square that fixed a clear landmark capable to colonize landscape (Figure 10).

Figure 10. General View and Composition, Cala Gogó, Calonge

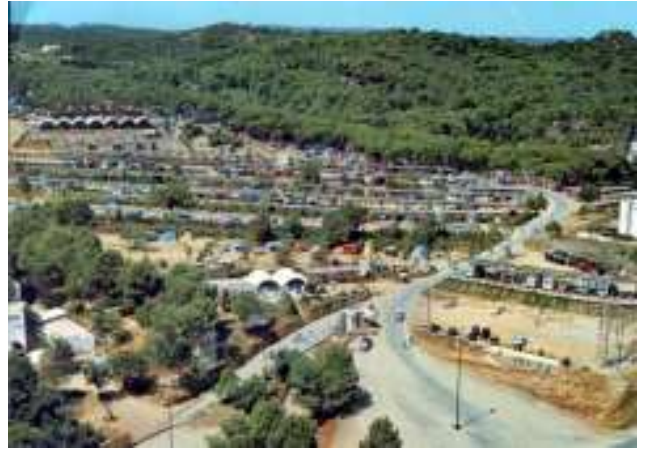

Source: Campsite private archive

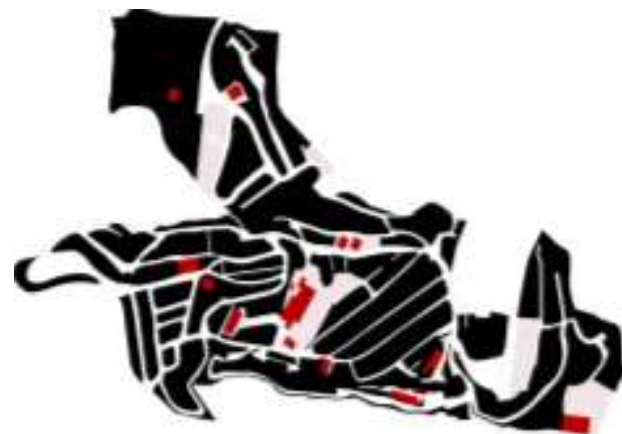

Source: By author.

As for typology, these two campsites could be considered as clear examples of temporal settlements, in completely different natural contexts. In both cases, roadways were designed and constructed in a pattern that followed the landscape characteristics. Private circulation was ensured on the basis of footprint distribution, almost rambling. In this context, it was necessary to consider a new hierarchy; an upper layer which should give order to the whole settlement and also unify the common buildings in a clear and direct way.

Based on this duality, architects designed these settlements to be living cities through an integrated project, taking under consideration all the different scales of action from territory to users. In both projects, the architects developed accurate strategies being in balance with the environmental surroundings. Finally, decisions about what to do and how to do it were mainly determined by landscape complexity. 


\section{Formal Architecture}

"The excellent quality of those builders gave us a large range of possibilities, but at last reduced by a strong lack of materials. Thus, the work had to be done in a simple way with few resources but with highflying ideas".

Architect Josep Puig Torné (Puig 2002)

Architecture applied in campsites adopted many elements of the tradition of Mediterranean architecture: configuration of threshold and shaded entrances; brick walls plastered in white as a protection from adverse climate conditions; local solutions for ground adaption, such as dry stone walls; clear geometry and pure volumes; singular constructive techniques, such as the Catalan vault; cheap prefab materials, such as ceramic lattices, asbestos or metal sheets. Thus, its traditional origin was one of the most valued qualities in addition to the incorporation of coeval modern criteria, which provided functional concepts, order and geometry.

This architecture was controlled at all scales. It also was free and open to innovation in the construction of buildings that provided all services in order to keep landscape untouched. In this way users felt comfortably absorbed by landscape. In a larger scale, common buildings were used to serve the various needs of the campers, including services related to reception, supplies, leisure, shopping or sports. In a closer scale, private buildings, such as toilet and shower facilities, provided private conditions where users could be completely exposed, even naked, in a protected environment. Thus, circulations between private plots, common buildings and sanitary pavilions had to be direct and clear. A combination of these three elements completed the dwelling in a dynamic system.

In El Toro Bravo, architect Francesc Mitjans designed each building according to the specific services it would host and its particular conditions. The common link between them was their formalization on the basis of regular geometry and local constructive systems and materials. However, each of these geometries varied according to the several activities performed within their context. In fact, they also differed in their particular relation to the environment (Figure 11).

Figure 11. Supermarket, Reception and Water Tank, El Toro Bravo

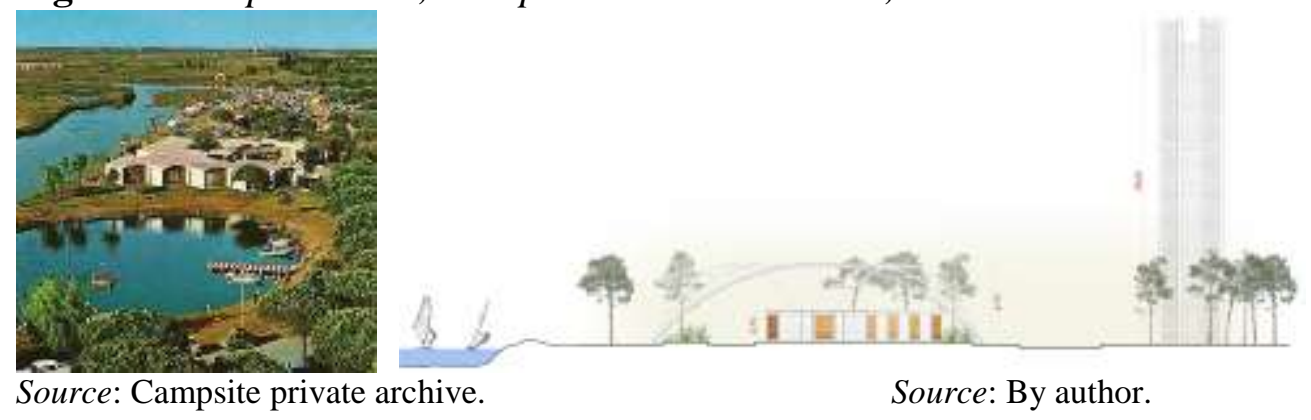


The main entrance was defined by the reception building, located under a steel canopy, and the water tank in the form of a brick tower. Due to their location and design, these facilities became landmarks both for campers and foreign visitors. Close to the entrance, the supermarket was developed as a series of Catalan vaults, with entrances and courtyards being in balance with their natural boundaries. On the other hand, the sanitary pavilions were constructed as square open-air buildings. However, inner privacy from the outside was provided by brick walls, establishing a subtle contrast with natural context (Figure 12).

Figure 12. Sanitary Pavilion, El Toro Bravo

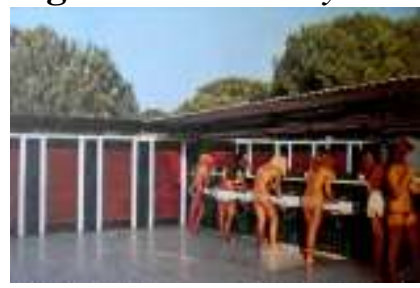

Source: Campsite private archive.

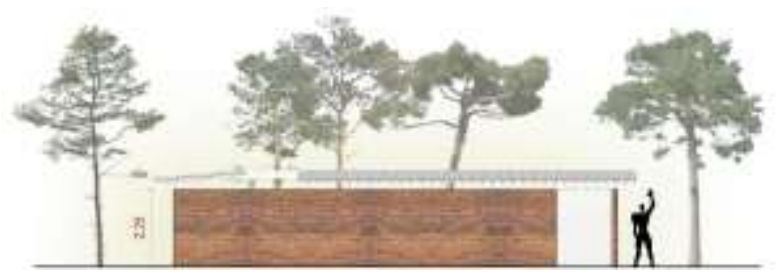

Source: By author.

In the case of Cala Gogó, architects Antoni Bonet Castellana and Josep Puig Torné used a unique system to design all the buildings, so that the whole settlement would have a unique character and identity. Based on a repetition of Catalan vaults supported by stone pillars, these buildings were designed under a flexible structure suitable for different uses. Furthermore, all these buildings were painted in white, so formal differences between them were set up only by their scale and their surroundings.

All common uses were integrated in one building located in the center of the campsite. This building provided all different services with this simple and flexible composition, but was covered by a cantilever (Figure 13) so that, it was converted into a clear reference and a distribution node for the whole campsite. On the other hand, sanitary pavilions were distributed all along the campsite following the same building typology. Although the main building was located in a specific spot so as to be seen from everywhere, these pavilions were located under pathway levels providing privacy by taking profit of topography (Figure 14).

Figure 13. Commercial and Common Uses Building, Cala Gogó
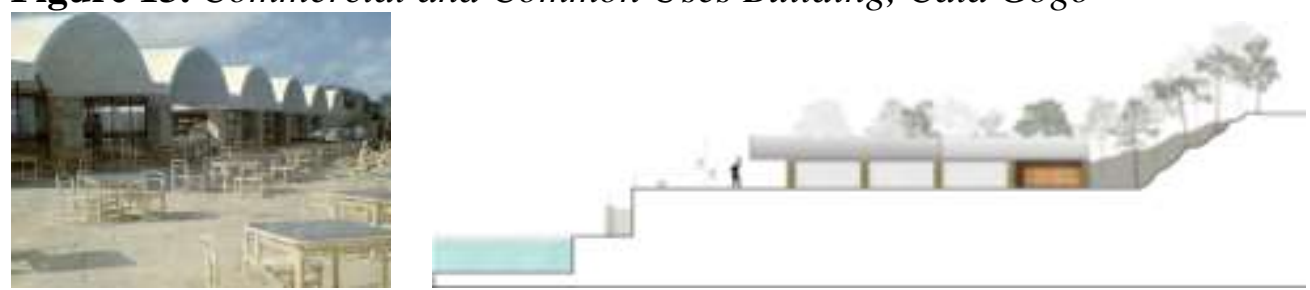

Source: Campsite private archive.

Source: By author. 
Figure 14. Sanitary Pavilion, Cala Gogó

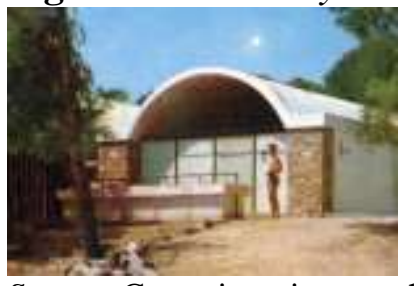

Source: Campsite private archive.

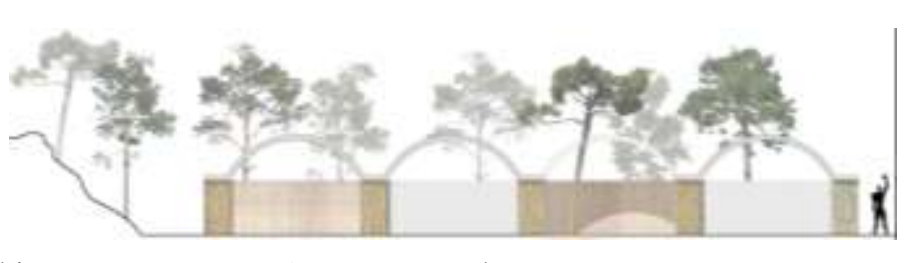

Source: By author.

By the time these campsites were built, constructive difficulties made geometric control and clear composition an important priority in many of these proposals. These considerations led to method of construction based on the merging of innovations and old techniques. Most of buildings were based on grids or geometric regular networks and were built with traditional Mediterranean materials such as stone, brick, wood or clay.

In both campsites, architects transformed tourism settlements towards a building typology closer to natural environment. These modules were thought of as places in which users could satisfy their needs in a communal context. Building open typologies -without doors and roofs floating over wallsemphasized these uses and added an adequate value for the original campsite features. This livable atmosphere closely related to the surrounding environment was kept by the usage of Mediterranean courtyards with thresholds, so the sky and trees were also included in architects' designs.

\section{Informal Occupancy}

"People in a campsite know that even if there are no walls, from here to here is my home, and from here to there is somebody else's. I think that living in a campsite also teaches you to live together with others"

\section{Interview to a user of a campsite (Ollé and Mataix 2011)}

Although campsite singularity lies in its being close to nature, its development needed formal architecture in order to solve the emerging issues related to the city system and also to establish the rules of the plot system that users had to follow. In some cases, architects facilitated this adaption and established an upper layer that could not be modified by the informal intervention of users, mostly being dynamic and spontaneous.

One of the most important differences between the two study cases is related to this formal intervention on designing private plots. This difference emerges due to the variety in the concrete characteristics of natural environment on each campsite. In El Toro Bravo, plots were distributed under existing trees that naturally provided shade and organization. This produced a close approach of the user to its context, and also a higher need of adaptation by means of informal architecture; privacy, wind protection and views.

Under the pine forest, every footprint was located between trunks and enough space was saved for lightweight lodging and private transport. The 
regular height of trees generated a virtual natural ceiling that let circulation of fresh air and also framed sea views. Its density as well as its shadow enabled the architects to place lodgings in all different orientations so that footprint distributions were easier to follow than it seemed because of the different shapes and dimensions of plots (Figure 15).

Figure 15. Private Plots and Informal Occupation, El Toro Bravo
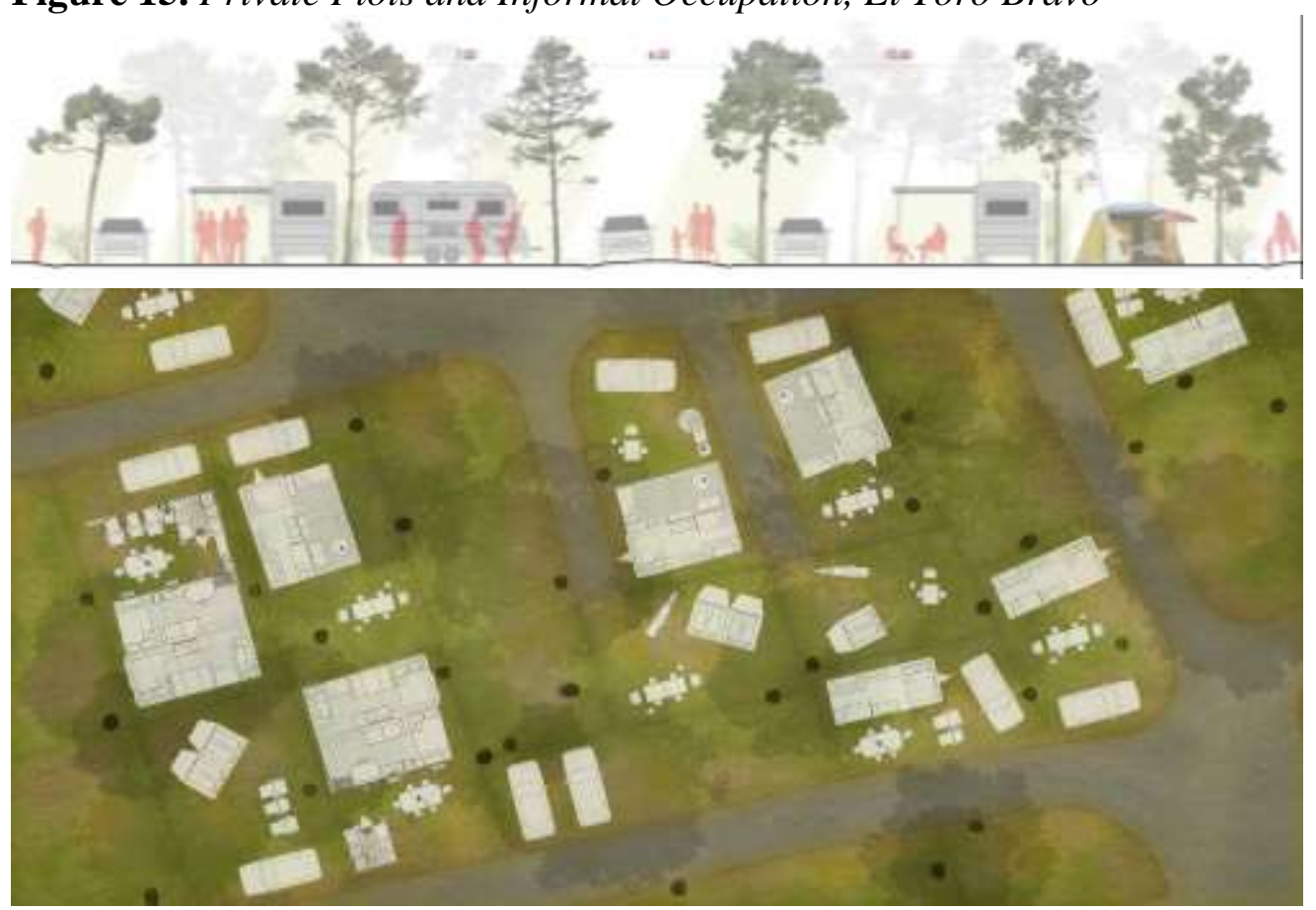

Source: By author.

In the case of Cala Gogó, architects defined some formal issues that configured an upper order, related to the campsite as a whole. The usage of canopies added shade, but also privacy and controlled views. However, users also had to develop their informal adaption in each plot, with these interventions remaining under a second layer, less visible and more protected (Figure 16). Working with topography also led to the gentle transformation of the environment and its pathways, in order to install fountains and other elements related to water supply. 
Figure 16. Private Plots and Informal Occupation, Cala Gogó
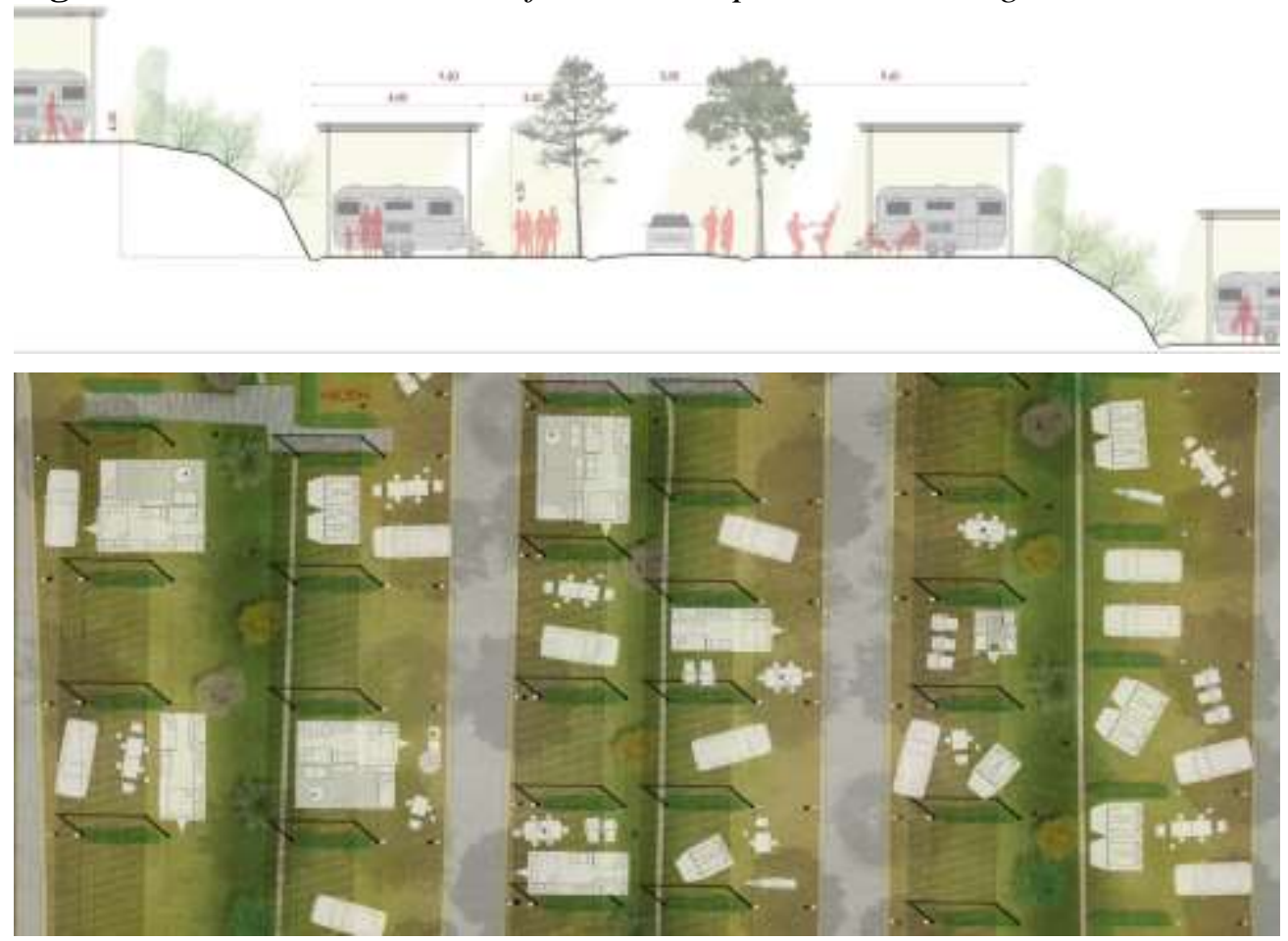

Source: By author.

Both case studies, El Toro Bravo and Cala Gogó, were campsites developed by great architects that designed well-organized plans having as a target to keep the balance with the environmental surroundings. The main objective of these plans was to let users occupy their private plots in an informal and particular way, sometimes even singular. By means of personal experience and the simple use of context resources, users could adapt all those features into their plots, with shadow and flat plane as basic conditions of dwelling in nature.

\section{Conclusions}

"The good thing about informal technology is that flexible architecture concepts remain for years. [...] In a nomadic town like this, the inhabitant rents the right to occupy this land for a while. Nobody owns the land".

Interview to Architect José Miguel de Prada Poole (Ollé and Mataix 2011)

These campsites were clear examples of a type of settlement that provided a temporal and protected stay at the natural landscape. Under an adequate architectural design, these campsites kept a good relation between natural environment and new settlements. Furthermore, these two cases analysed here raised the issue of the natural value of campsites as a system of lightweight occupation, sustainable from its origin. 
The analysis of these two case studies reflected that an approach from different scales was necessary to establish this close relationship between campsites and nature. From the formation of the large territory to the specific details of the settlement, architects had to define those characteristics provided by landscape in order to reach a flat plot protected from the sun. In this sense, by means of urbanism and architecture, it was necessary to fix a hierarchy that could add a new layer over existing context in order to convert it into a temporary city.

In relation to buildings, architects concentrated common uses and services in a single facility as an appropriate way of keeping the natural surroundings of the sites unaltered. Furthermore, these buildings were functionally clear and simple, with efficient circulations and with open, easy to access public spaces. Easy user access to the facilities was considered an issue of high importance, so that large buildings were disintegrated in small modules. This way, architects could easily design the buildings' boundaries and access points in relation to the landscape and human factors.

In both campsites, buildings were designed based on the traditional Mediterranean architectural criteria, while also adopting a certain interpretation of these local systems from a cutting edge point of view. Lack of resources and need for innovation forced the use of singular compositions: bricks were used in different positions creating lattices, doors and windows were transformed into shadowed holes, entrances were based on thresholds, handy structures encouraged curved designs and open-air schemes let users get in contact with nature from indoors.

In this sense, the given natural context established the starting point from which architects defined buildings and features for future users in their private plots. Basic needs were solved by pavilions, designed with the use of tools of formal architecture. However, users had to mildly transform their plots in order to satisfy their dwelling needs. Existing trees, water supplies, sights, orientation or location of lodging and cars were basic characteristics that determined user criteria for inhabiting the plots. This informal architecture was based on personal experience. Thus, it was dynamic and unpredictable (Figure 17).

Figure 17. Informal Occupation of Private Plots, El Toro Bravo

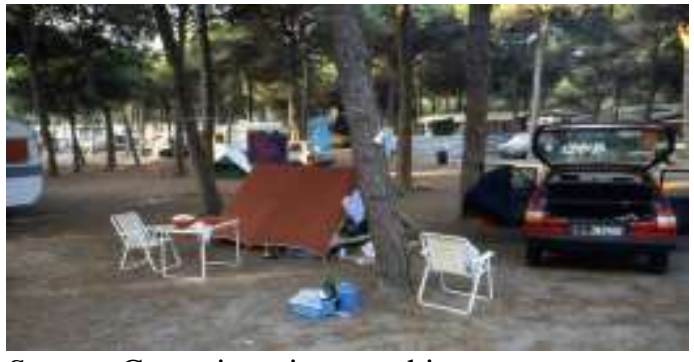

Source: Campsite private archive.

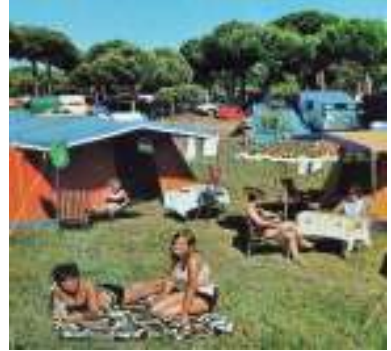

Source: Campsite private archive.

However, the evolution of tents and caravans into prefab lodging through time limited the adaptation of users and also transformed temporal settlements into hermetic sectors that could not evolve following original criteria. The 
architectural design of lightweight formal elements in the campers' plots enabled the comprehension of campsites as a unity, rather than a site for exclusive user development. As lightweight formal architecture was developing to satisfy campers' needs, less spontaneous or permanent solutions would emerge in the context of informal architecture. Thus, such solutions would remain under a second layer and in a less stable way (Figure 18).

Figure 18. Permanent Housing and Formal Designed Elements

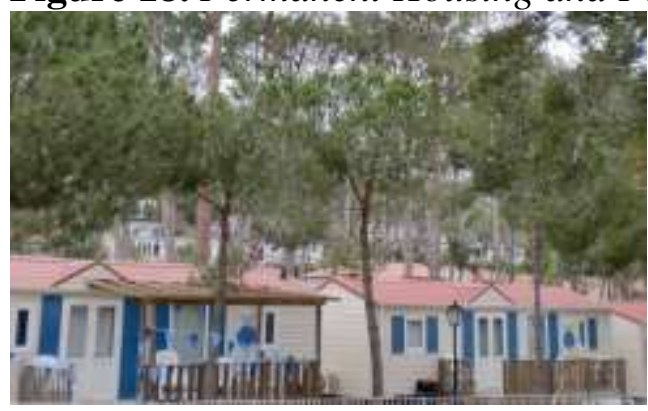

Source: By author.

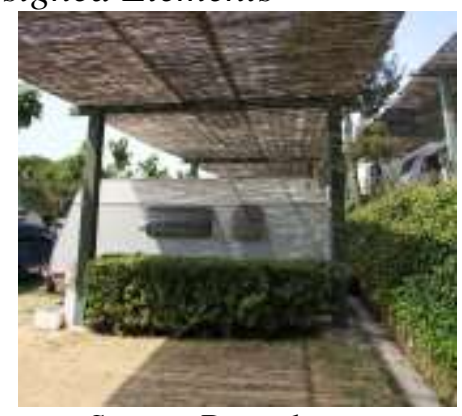

Source: By author.

The analysis of these two case studies reflected that both campsites were designed as living systems capable to preserve the environment and the original conditions of its natural appearance. A clear example of the values adopted by the campsites due to landscape recuperation is El Toro Bravo. In 2005, it was closed due to an enlargement of Barcelona's airport (Calderé 2013). Since then, this sector has been converted into the National Protected Natural Area of dunes of the Llobregat delta.

On the other hand, the Cala Gogó campsite still remains active and its presence and its value has also developed positively. Campsite evolution led to the addition of other public services nearby, such as restaurants, dancing clubs or supermarkets. This increase of services also accelerated the installation of new campsites and other types of formal tourism, such as hotels and apartments. The combination of these different settlements has led to the creation of a territory of great natural beauty. Although the campsite is extensive, its impact on the landscape in the long term remains much less harsh than in other intensive developments.

In conclusion, it is important to note the flourishing interest of the subject that the present paper studies: from campsite origins towards their future developments. This fixes a new step forward in order to catalogue and analyze those other campsites projected by great architects in the Catalan coast during the 1960s. This analysis follows the same criteria showed in this study, in order to comprehend the main issues of designing campsites in other natural environments, with different characteristics.

By the means of this analysis of projects it would be possible to establish a series of design criteria for campsites. These could take into account the original values of the campsites and could relate them to the current needs of tourists and tourism. The natural coastal environment in Spain has been deeply damaged for 30 years by formal tourism. This should not happen again, so 
campsites can be used as a reference for future developments. As architect José Miguel de Prada Poole said in an interview for a documentary called "Camping, Caravanning, Arquitecturing" (Ollé and Mataix 2011):

"Humanity, if we generalize, consists of two types of people: nomads and sedentary. And nomads are very few, but they are those who open new paths. What we must do is study all of these movements that are close to us [campsites], which are even history. Because by seeing how it can be improved, we all could make it even stronger".

\section{Acknowledgements}

All data used and analyzed in this paper are part of author's Ph.D. Thesis (in process). This information was collected during 2013-2015 in collaboration with R\&D project of IAM Group (ETSA La Salle, Ramon Llull University) called Strategies for Sustainable Regeneration of Tourism Settlements in the Mediterranean Coast which is funded by the Ministry of Economy and Competitiveness - Secretariat of State for Research, Development and Innovation, Spanish Government. Author's Ph.D. Thesis is directed by Ph.D. Anna Martínez Duran and it is supported by the FI DGR2015 grant (reference 2015FI_B 00973), funded by European Social Fund and Secretary for Universities and Research of the Ministry of Economy and Knowledge of the Generalitat of Catalonia, Catalan Government. The original mapping and aerial photographs used were provided by the Cartographic Institute of Catalonia (ICC). Some pictures and data used were provided by Historic archives such as COAC (Official College of Architects of Catalonia), CEC (Hiking Centre of Catalonia) and municipalities of Viladecans and Sant Antoni de Calonge. Some pictures and data used were provided by private archives such as the Cala Gogó, the El Toro Bravo and the architect Josep Puig Torné. The author wish to acknowledge the helpful comments from two anonymous referees.

\section{References}

Barba R (1992) Les grans formes del Territori. O... perquè parlar sempre de l'interior de la ciutat? [The large forms of the Territory. Or... why speak always about the interior of the City?] Quaderns d'Arquitectura i Urbanisme [Notebooks about Architecture and Urbanism]. 194: 41-43. Retrieved from http://bit.ly/1Klena9

Calderé X (2013) Juliol de 1958. El naixement del primer càmping de Viladecans [The birth of the first campsite in Viladecans]. Punt de Viladecans [Dot of Viladecans]. 65. Retrieved from http://bit.ly/1Mm88Fu

Codina P (1964) Camping. Tècnica i orientacions generals $i$ coneixements necessaris [Camping. Guidelines and technical knowledge required]. Barcelona: Rafael Dalmau.

COAC (1992) Infiltracions [Infiltrations]. Quaderns d'Arquitectura i Urbanisme [Notebooks about Architecture and Urbanism]. Barcelona. No. 195. Retrieved from http://bit.ly/1NngATF.

Dern J (1992) Turisme culte? Alguns comentaris sobre el col.loqui de Leeuwarden, Holanda [Cultured tourism? Some comments on the discussion of Leeuwarden, 
Netherlands]. Quaderns d'Arquitectura $i$ Urbanisme [Notebooks about Architecture and Urbanism]. 194: 20-27. Retrieved from http://bit.ly/1Klena9

Gaspar J (1929) Aerial views of Catalonia. Institut Cartogràfic de Catalunya [Cartographic Institute of Catalonia].

IAM Group (2012-2014) R\&D Project "Strategies for Sustainable Regeneration of Tourism Settlements in the Mediterranean Coast". School of Architecture La Salle, Ramon Llull University. Barcelona: BIA2011-28297-C02-02.

IAM Group (2015) Estrategias Mediterráneas [Mediterranean Strategies]. School of Architecture La Salle, Ramon Llull University. Navarra: Ulzama.

Miranda MJ (1985) El camping, la forma más reciente de turismo [Camping, the most recent way of tourism]. Cuadernos de Geografía [Notebooks about Geography]. 37: 157-174. Retrieved from http://bit.ly/1IXUodw.

Ollé M, Mataix S (2011) Camping, Caravaning, Arquitecturing. Documentary and Itinerant Exhibition.

Puig J (2002) Arquitectura turística anys 60-70 [Touristic Architecture in the 196070s]. L'Arquitectura del Sol [Sunland Architecture]: 30-33.

Rodriguez C (1961-1963) Aerial views of SACE. Servicios Aéreos Comerciales Españoles [Spanish Aerial Comercial Services].

Valverde A (1997) Evolución histórica, origen y significación de la pineda litoral del delta del Llobregat (s.XVI-XIX) [Historical evolution, origin and significance of the coastal pine forest of the Llobregat delta]. Spartina. El Prat. No. 3: 63-101. 
